\title{
El palo de jocote
}

Francisco Rodríguez Vargas

$\mathrm{E}$ $\mathrm{n}$ los albores del siglo veinte, en un remoto pueblito de Grecia llamado Santa Gertrudis, el humilde matrimonio de Odilíe y Leonardo se llevaba a cabo, sin más testigos que Dios, su amor y el cura que los casó.

Al cumplir Odilíe los quince años, nació el primer retoño de su amor. Leonardo trabajaba con pasión y ahínco para abrir el vientre de la madre tierra y fertilizarla con granos y semillas. Esta, agradecida, paría muchas cosechas para que la familia viviera y se multiplicara.

Después de muchos años de feliz matrimonio y de compartir lágrimas y tristezas juntos, Odilíe se convirtió en parra fecunda y parió quince retoños más. Solo le alcanzaba el tiempo para atender a su numerosa familia. A pesar de tantas limitaciones y pobreza, no había una familia más feliz sobre la faz de la tierra, pues el amor verdadero es el origen de la felicidad.

Odilíe amaba los jocotes tronadores, pero como debía viajar hasta Grecia para conseguirlos, decidió sembrar un palito en el patio de su humilde rancho. Pocos años después, aquel árbol produjo los jocotes tronadores más grandes, rojos y apetitosos de todo Santa Gertrudis. Tanto fue así que hasta gente de la capital visitaba su humilde ranchito en busca de los famosos jocotes. Esto, por supuesto, era una bendición para ayudar a su esposo a mantener la catizumba de güilas.

Por otro lado, en la ciudad de San José, Flor de María, hija única de un acaudalado matrimonio, se va a especializar a una prestigiosa universidad europea y no cumple así con la tradición social de la época de casarse y convertirse en ama de casa. Al contrario, se vuelve una famosa y prestigiosa agrónoma.

Flor, o como la llamaban cariñosamente sus amigos cercanos, Pollita, realizaba giras de campo por todo el país como parte de sus labores cotidianas. Cierto día, por azares del destino, arribó a Grecia. Escuchó atentamente los elogios que en el pueblo se hacían del famoso palo de jocote de Santa Gertrudis. Tal fue su curiosidad de agrónoma que se enrumbó hacia allá para ver con sus propios ojos aquel prodigio del que todo el pueblo comentaba. 
Al llegar, se hizo pasar por otra clienta más que quería comprar tronadores. De inmediato, cayó en gracia con Odilíe, a quien le pidió que la llevara a ver el palo de jocote. Odilíe se lo mostró muy orgullosa. Pollita estaba tan admirada del tamaño de los jocotes, que solo acató a abrir su boca en señal de admiración.

El tiempo transcurrió y Pollita se hizo muy amiga de la familia y ayudaba con la compra de los frutos. En la época en que no había cosecha, les seguía ayudando a paliar su pobreza.

Debido a sus constantes viajes a la provincia de Alajuela por asuntos de trabajo, Pollita se puso de acuerdo con la familia para alquilar un cuartito en el ranchito, tan lleno de niños, que más bien parecía un kínder o una guardería.

Los padres de Flor de María habían fallecido mucho tiempo atrás. En este humilde hogar, Pollita descubrió el significado de la verdadera felicidad y el amor. Se convirtió en una hija y una hermana más de la ya tan numerosa prole.

En un frío y ventoso diciembre, Pollita le comunicó a la familia que ya se pensionaba e iba a continuar viviendo en su casa de la capital. La despedida fue muy triste. Hubo de todo: besos, caricias, lágrimas y hasta una comida especial que incluía un chompipe criado por Odilíe .

En la madrugada en que Pollita partía para la ciudad capital, Odilíe le preparó un suculento desayuno. El regalo de despedida consistía en un palito de jocotes tronadores ya grandecito. Para Pollita, no podía haber mejor obsequio que ese, pues lo había deseado tantas veces pero por pena no se había atrevido a pedirlo.

Partió con el corazón roto en mil pedazos por tener que abandonar a aquella que se había convertido en su familia, su mundo y la única felicidad que conoció.

La familia también quedó destrozada, ya que quien era como su hija mayor los abandonaba para siempre.

El tiempo siguió su curso inexorable y los años transcurrieron uno tras otro. Desde la partida de Pollita, las cosas empeoraron. La pobreza clavó sus garras y dientes y el terrible flagelo del hambre hizo sus víctimas a la pobre y humilde familia.

Muchos de sus integrantes fallecieron por desnutrición. De aquella gran familia de dieciséis miembros, solo sobrevivieron nueve. Los fallecidos se convirtieron en ángeles que velaban y suplían las necesidades de sus padres y hermanitos.

De Pollita solo les quedaba un gran recuerdo y una imperecedera gratitud por su bondad y nobleza. Solo el árbol de jocote permanecía impasible como un recuerdo de los buenos tiempos en que los dieciséis miembros y, posteriormente, la número diecisiete se unió a la familia para disfrutar de su sombra, comer sus dulces frutos y observar las aves que también llegaban a disfrutar del festín que la madre natura les obsequiaba.

Para colmo de males, un lluvioso mes de octubre, un rayo cayó sobre el palo de jocote y lo secó para siempre. Y como los males siempre vienen acompañados, el fuego posteriormente arrasó con el ranchito de la familia, la cual se vio obligada a vivir entre bolsas de plástico, latas de zinc viejas y palos podridos. El viento y la lluvia se colaban por las hendiduras y hacían tiritar de frío a los miembros de 
la familia quienes debían dormir juntos para darse el calor que los trapos viejos $\mathrm{y}$ sacos de gangoche que usaban como cobijas no les brindaban.

Mientras que por otro lado, Pollita seguía con su monótona y solitaria vida en la jungla de cemento como solía llamar a la capital. Uno de tantos días, sintió un terrible dolor en el vientre que la obligó a visitar el hospital. Le prescribieron muchos exámenes, pruebas y análisis.

Luego de algunos meses de sufrimiento y angustia, finalmente le dieron la peor noticia de su vida: tenía cáncer de útero y solo le restaban unos pocos meses de vida. La noticia fue devastadora. Solo atinó a pensar en la familia de Santa Gertrudis a la que tanto amaba y quienes la amaban también.

$\mathrm{Su}$ primer deseo fue regresar. No obstante, hacía tanto tiempo que no sabía nada en absoluto de ellos. El complejo de culpa y el remordimiento que sentía por haber perdido toda relación con esta familia la hicieron desistir de su primer impulso.

Luego trató de organizar sus ideas y decidió que la mejor forma de demostrar su amor y agradecimiento por aquellos que tanto amaba, era visitar a un abogado y heredarles sus numerosas posesiones materiales.

Fue a consultar con un prestigioso abogado que se había graduado en la misma universidad europea que ella y quien, además, era su amigo. De inmediato se procedió a hacer todo el papeleo legal y las propiedades y bienes les fueron transferidos a Odilíe, Leonardo y familia.

El tiempo de vida se fue acortando, los dolores y sufrimientos se hicieron el pan nuestro de cada día para Pollita. Pero, a pesar de las adversas circunstancias, su corazón rebosaba de gozo y alegría , pues por fin iba a ser capaz de devolver un poco de felicidad a la familia que la había acogido como hija y le había enseñado el verdadero significado del amor y la felicidad.

Pocos días antes de reunirse con Dios, Pollita envió a su chofer con la dirección exacta de la familia en Santa Gertrudis. Sus instrucciones fueron muy precias: "Se viene con toda la familia en avioneta y mi ayudante personal los recoge en el Aeropuerto Tobías Bolaños. Bajo ninguna circunstancia, les diga que me estoy muriendo".

Después de muchos ruegos del chofer, la familia aceptó la invitación para ver a Pollita y, de paso, conocer la capital. Se preguntaban cómo se encontraría su hija adoptiva luego de tanto tiempo de no verla ni saber de ella.

Salieron de su rancho en plena oscuridad para llegar lo más temprano a Alajuela y de ahí " montase en el pájaro de fierro ", como le decían a la avioneta.

Después de muchas peripecias y sustos, llegaron a la capital. Se quedaron boquiabiertos y estupefactos ante lo que vieron en San José. Nunca, ni tan siquiera en sueños, se podían haber imaginado que una ciudad tuviese tanto lujo y fastuosidad como la capital.

Después de viajar por San José, llegaron al Barrio Amón, lugar de residencia de Pollita. Cuando llegaron a la puerta de la casa, les dio temor la grandeza y el lujo de la residencia y, sobre todo, de aquellas personas enfundadas en uniformes blancos, quienes les recordaban a los médicos y enfermeras del Hospital de Alajuela. 
Luego de un rato, pudieron ver a su amada Pollita. Nunca jamás se imaginaron encontrarla en aquel estado tan deplorable. Mas parecía una muerta en vida que la Pollita que recordaban con tanto amor. Su cara estaba pálida y demacrada como la cera, le colgaba la piel de los huesos y sus ojos estaban totalmente hundidos. Al verla, Odilíe no pudo reprimir las lágrimas y estalló en llanto. Toda la familia desfiló ante el lecho de la enferma. Fue un reencuentro muy doloroso.

Pollita le suplicó a Odilíe y la familia que no la abandonaran y se quedaran a vivir con ella antes de su partida. Odilíe aceptó. Este fue el mejor consuelo y un bálsamo para las heridas del cuerpo y el alma de la moribunda. Su madre adoptiva la cuidó día y noche y no permitió que nadie más ocupase su lugar.

Unos días antes de morir, Pollita reunió a toda la familia y les informó acerca de su última voluntad de que heredaran todas sus posesiones, propiedades, bienes materiales y cuentas bancarias. El abogado amigo suyo sería el encargado de cumplir su última voluntad mediante un testamento ya preparado.

La mañana del día antes de encontrarse con su Creador, Pollita le pidió un último y muy especial favor a Odilíe: que la ayudara a levantarse y llegar hasta el patio trasero de la casa. Odilíe la llevó casi a rastras. Al llegar al patio, Odilíe lanzó un grito de asombro que resonó por toda la vivienda.

Toda la familia corrió en tropel hasta el patio. Allí se llevaron la sorpresa más maravillosa de sus vidas: el palo de jocote los estaba esperando con sus dulcísimos tronadores de los que todos disfrutaron. Pollita les dijo que ese era el árbol que Odilíe le había obsequiado cuando partió para San José, que los había unido en la vida y que ahora los uniría aún más en la muerte y después de esta, pues el palo de jocote era el símbolo del amor verdadero que trasciende el tiempo, la muerte y la eternidad.

A la mañana siguiente desfilaba un cortejo fúnebre con dirección al Cementerio Calvo. Todo parecía normal para la triste despedida: luto, dolor y lágrimas acompañaban a los dolientes.

No obstante, había algo que no estaba acorde con la solemnidad del evento. La familia de Pollita estaba sonriente y llevaba cada uno de ellos un jocote tronador en la solapa de sus negros trajes. Las proféticas palabras de la difunta se cumplieron al pie de la letra. El árbol de jocote los había unido en la vida y también los uniría en la muerte. Un rictus que imitaba una sonrisa apareció en el rostro de la fallecida. 